\title{
ADIÓS, SARMIENTO. EDUCACIÓN PÚBLICA, IGLESIA Y MERCADO
}

Por Adriana Puiggrós. Buenos Aires: Colihue, 2017, 379 páginas. ISBN 978987-684-767-4.

\section{A MODO DE INTRODUCCIÓN}

El pensador argentino Aníbal Ponce alguna vez definió a Sarmiento como «el eje a través del cual giraba todo». ${ }^{1}$ No se puede negar que la impronta del sanjuanino "padre del aula» sigue atravesando a la educación argentina, y de alguna manera este ensayo escrito por Adriana Puiggrós viene a ratificarlo. Comenzar esta reseña con una cita de Aníbal Ponce, recuperada en las páginas de Adiós, Sarmiento, es una de entre las muchas posibles maneras de darle inicio a este escrito. En particular, de esa cita me interesa destacar dos cuestiones. En primer lugar, las palabras de Ponce ratifican la centralidad de la figura del pedagogo argentino, gestor del sistema de instrucción pública, que se manifiesta en el título del ensayo. Aunque no estamos hablando de una biografía (la continuación del título es con los conceptos de «Educación pública, Iglesia y mercado»), la figura de Sarmiento acompañará todo el desarrollo del libro.

En segundo lugar, porque Aníbal Ponce recuperó al sanjuanino desde un pensamiento de izquierda liberal (corriente que compartió con Luis Iglesias, que reconoce en José Ingenieros uno de sus precursores, y que incluye a pedagogas como Delia Etcheverry), ${ }^{2}$ de profunda raigambre en la pedagogía argentina. Y esto muestra sólo una de las varias recuperaciones

\footnotetext{
${ }_{1}$ Adriana Puiggrós. Adiós, Sarmiento. Educación pública, iglesia y mercado (Buenos Aires: Colihue, 2017), 104.

${ }^{2}$ Una muestra del alineamiento de esta corriente con el pensamiento sarmientino puede verse en las siguientes palabras: «Sarmiento está en la entraña de nuestra escuela popular, hasta donde en su época era posible llegar al pueblo. Arquetipo de hombre genial, de civilizador del siglo XIX, fue personalidad con tantas facetas que siempre brinda rico material al comentario. Se le escruta desde
} 
del pensamiento sarmientino: en algún sentido, todo pensamiento pedagógico que disputara la legitimidad del campo educativo argentino, debía encontrar en Sarmiento su fundamento. Por eso, hallamos reivindicaciones desde el catolicismo, desde el nacionalismo, desde el liberalismo y desde la izquierda, con todas las posibles variables producto de su entrecruzamiento. Y en este sentido, si bien Puiggrós manifiesta sus propias posiciones, las diversas perspectivas que a lo largo de la historia argentina disputaron posiciones y construyeron significados sobre la figura de Sarmiento están presentes en el texto de una manera detallada, amplia y respetuosa. Razón esta última por la cual el libro constituye una herramienta para profundizar en ideas y debates de la historia de la educación argentina, especialmente para quien se acerque por primera vez a ellos.

Si bien Adiós, Sarmiento es un texto que difiere de sus trabajos «canónicos», lleva consigo la marca puiggrosiana: en sus párrafos se identifican las principales preocupaciones de la autora. Es un texto escrito con la urgencia de la batalla de ideas contra las que la autora quiere discutir. Frente a un panorama latinoamericano de golpismos mediático judiciales y avances de las derechas más reaccionarias, el texto es una voz de alerta en donde la autora recoge años de experiencia en la política educativa, tanto desde la gestión como desde la tarea legislativa.

Una de las diferencias está en que en este texto no hay una fuerte presencia de marcos teórico-conceptuales. El bagaje teórico de Imperialismo y educación en América Latina (1980), La educación popular en América Latina (1984) o Sujetos, disciplina y currículum (1990) pasa a un segundo plano frente a la urgencia de un país y una región que nuevamente adoptan medidas tendientes hacia la mercantilización de la educación y la destrucción de los sistemas de instrucción pública. Las prácticas, los sentidos, y los discursos pedagógicos, los sujetos y las luchas por la hegemonía y los conflictos del campo educativo dejan lugar a los problemas de las políticas públicas educativas, con el claro objetivo de establecer una voz de alerta en un contexto en el que, «dada la apertura del mercado educativo será cada vez más fácil comprar un diploma de enseñanza media».3

puntos distintos y orienta en los caminos oscuros del quehacer» [Delia Etcheverry, Los artesanos de la enseñanza moderna (Buenos Aires: Ediciones Galatea-Nueva Visión, 1958), 29].

${ }_{3}^{3}$ Puiggrós, Adiós, Sarmiento, 346. 


\section{LAS TRES PARTES DE ADIÓS, SARMIENTO}

La primera parte consiste en un análisis detallado y con una gran rigurosidad histórica de las distintas posiciones respecto de la responsabilidad de educar en el período post independentista y de conformación del estado nacional argentino, remarcando los distintos actores, representantes de diversas corrientes y posiciones. De esta manera entra en juego Sarmiento, heredero de las contradicciones del despotismo ilustrado y las tensiones entre el liberalismo y la religión, junto a una serie de personajes como Mora, Echeverría, Alberdi y Estrada, quienes representaron distintas posiciones respecto del rol que debían tener tanto el estado como la Iglesia católica en materia de educación.

De más está decir que estamos hablando de una élite en su gran mayoría católica, encontrándose las diferencias no en cuanto a la adscripción religiosa sino en torno a la responsabilidad última sobre la acción educadora. Esto aparece reflejado en las palabras de la autora sobre la discusión en el Congreso Pedagógico de 1882 (del que saldría una propuesta de ordenamiento legal para el sistema educativo), que no fue entre ateos/positivistas y católicos, sino entre racionalistas y católicos: «Ni siquiera a Sarmiento se le ocurría enfrentar a la religión católica».4

En esta primera parte, Puiggrós llega al hueso del problema histórico de la relación entre el estado y la Iglesia católica en Argentina, explorando razones de esa relación tan compleja entre una élite gobernante liberal y una jerarquía eclesiástica completamente inserta en el entramado social y político, que no es solamente un actor de poder contra el que esa élite deberá disputar posiciones, sino que, como una herencia de la legitimación de la Iglesia católica a la monarquía, el estado nacional en proceso de conformación delegó funciones en esa institución. Como afirma la autora, «se estimulaba la expansión de las redes escolásticas, puesto que, si la modernidad escolarizante podía alcanzar a la conciencia del ciudadano, el discurso religioso tenía la capacidad de dominar los espíritus». ${ }^{5}$ En el proyecto del orden y el progreso, no era menor que una institución como la Iglesia pudiera garantizar cierto

\footnotetext{
${ }^{4}$ Puiggrós, Adiós, Sarmiento, 106.

${ }_{5}^{5}$ Puiggrós, Adiós, Sarmiento, 79.
} 
orden, aunque esto significara resignar postulados de la filosofía del progreso y la ciencia.

La institución católica era una institución compleja que también presentaba intereses y disputas, baste la mención al conflicto que mantuvo la Orden de los Jesuitas con la corona española que derivó en su expulsión de España y los territorios coloniales americanos en 1767. El poder desarrollado por la Iglesia católica desde las épocas de la colonia no podía ser desconocido por la élite liberal que luego del proceso de independencia tomó en sus manos las riendas de la nueva organización política. La fe católica estaba extendida en todos los niveles de la sociedad, desde los sectores populares hasta los sectores dirigentes, razón por la cual cualquier disputa con esa institución debía ser producto de cálculos y decisiones justificadas.

Sarmiento conocía las raíces del catolicismo en la sociedad. Se había formado en esa matriz, además de pertenecer a su familia miembros de la jerarquía eclesiástica provincial. Dice en su obra Recuerdos de provincia acerca de su tío:

un digno sacerdote, el presbítero don José Oro [...] se encargó de mi educación. Me enseño latín y geografía, y de nada se cuidaba más que de formar mi carácter moral y de instruirme en los fundamentos de la religión, y en los acontecimientos de la revolución de la Independencia, de la que él había sido parte. ${ }^{6}$

Por el lado de su madre tenía vínculos familiares con el presbítero Albarracín, con quien continuó su educación religiosa durante un año y medio con la Biblia, el estudio del «dogma, la disciplina y la moral religiosa. A este otro de mis tíos, no menos liberal que el primero, debí el complemento de mi educación religiosa, que el primero me había recomendado mucho». ${ }^{7}$ Otro personaje de la vida de Sarmiento que aparece en Recuerdos de Provincia es el cura Castro, ejemplo de pensamiento progresista, contrario a la censura, los castigos, y a las creencias populares opuestas al desarrollo civilizatorio. El cura Castro

\footnotetext{
${ }_{6}^{6}$ Domingo Faustino Sarmiento, Recuerdos de provincia (Buenos Aires: Sopena Argentina, 1966), 11.

7 Sarmiento, Recuerdos de provincia, 12.
} 
acaso con el Emilio escondido bajo la sotana, enseñaba a las madres la manera de criar a los niños, las prácticas que eran nocivas a la salud, la manera de cuidar a los enfermos, las precauciones que debían guardar las embarazadas, y a los maridos en conversaciones particulares o en el confesionario, enseñaba los miramientos que con sus compañeras debían tener en situaciones especiales. $^{8}$

Toda una anticipación en los inicios del siglo XIX del futuro programa higienista que implementaría la generación de Sarmiento cuando accediera al poder del estado nacional, hacia finales del siglo.

Lo que intento transmitir con esto es una síntesis del problema de los vínculos entre la religión y la élite liberal que se manifiesta a finales del siglo XIX y que está claramente reflejado en el libro de Puiggrós. Allí la autora da cuenta de una situación compleja que muchas veces en interpretaciones posteriores se simplificó como una disputa entre el liberalismo laico y el conservadurismo católico. En realidad fue mucho más que eso, con múltiples entrecruzamientos y actores con orígenes diversos que adoptan distintas posiciones, como Sarmiento y su cercanía a un catolicismo liberal, como acabamos de ver, o como José Manuel Estrada, cuya biografía bien reseña la autora, que deriva desde un catolicismo también liberal hacia posiciones que pugnarán por la enseñanza religiosa obligatoria.

También Puiggrós plantea la idea de que durante el siglo XIX ocurrió un proceso de erosión del poder hegemónico que la Iglesia católica ostentaba desde los tiempos de la colonia. Esa erosión no implicó una desaparición de su poder, ni mucho menos, sino una situación que podría denominarse como de empate. Surgidas otro tipo de instituciones que respaldarían al grupo dirigente, como la masonería, «la relatividad del poder de la Iglesia sobre los dirigentes políticos, queda a la vista». ${ }^{9}$

En definitiva, lo que no estaba en discusión en esa generación era el fondo religioso, la necesidad de la religión como ordenadora de la sociedad. De hecho, el texto hace referencia a puntos básicos de acuerdo,

\footnotetext{
${ }^{8}$ Sarmiento, Recuerdos de provincia, 102.

${ }_{9}$ Puiggrós, Adiós, Sarmiento, 109.
} 
como el consenso entre católicos y liberales sobre la necesaria presencia del estado en la construcción del sistema educativo, o la admisión de mecanismos como el de la representación popular en los consejos escolares.

Pero donde entran a calar las diferencias es en el lugar que debe ocupar la religión en el proyecto estatal de conformación de la sociedad.10 Como afirma la autora, «en América Latina había que crear la población». ${ }^{11}$ Por eso, lo común era un proyecto, no un a priori. Y por eso, porque la sociedad debía formarse a partir de elementos diversos, la religión debía estar subordinada a la política. ${ }^{12} \mathrm{Y}$ el proyecto político era el fomento de la inmigración, sin distinción de credos. El país debía poder albergar a católicos, protestantes, judíos, musulmanes y ateos. Lo que no estaba en duda era que el inmigrante debía someterse a la imposición de una nueva identidad nacional, la de la nación argentina. Eso era lo prioritario, por eso, lo religioso era secundario, aunque Sarmiento nunca haya dejado de «creer en la fuerza civilizadora de la religión actualizada en términos democráticos». ${ }^{13}$

Los últimos capítulos de esta primera parte pueden resultar un poco áridos en su lectura. Los detalles histórico-políticos que documentan estrictamente las palabras de la autora no deben desanimar. Aquí, reiteramos, es importante tener en cuenta que la élite que dirigía el país compartía la religión católica, que al interior de esa élite, e incluso al interior de las posturas católicas que se enfrentarían a las posturas liberales, racionalistas, o contrarias a la enseñanza religiosa obligatoria, había distintas posiciones, y que la Iglesia católica, si bien tenía poder e influencia en vastos sectores de la sociedad, ya no era la institución que

\footnotetext{
${ }^{10}$ Vale la advertencia para los lectores de otras geografías, sobre la diferencia en la relación entre el estado y la sociedad en los territorios europeos y en los americanos, en especial en lo que refiere a la construcción de una identidad nacional. Después de las independencias, la problemática de la conformación de lo nacional pasa a ser uno de los principales problemas durante todo el siglo XIX, cuestión que en mayor o menor medida en los países europeos ya venía tramitándose años antes. Además, vale la mención al hecho de que en los territorios americanos, y especialmente en los países del cono sur, los estados despliegan un proceso de intervención en la sociedad, formándola, del que la política migratoria es un ejemplo central y eje que va a definir el rol del estado en la educación y la decisión de la no obligatoriedad del catolicismo.
}

${ }^{11}$ Puiggrós, Adiós, Sarmiento, 172.

12 Puiggrós, Adiós, Sarmiento, 57.

13 Puiggrós, Adiós, Sarmiento, 70. 
monopolizaba los resortes del poder hacia finales del XIX. Esto dará lugar a la situación de empate a la que se hizo referencia previamente. Porque si bien el saldo de las discusiones fue desfavorable para las posiciones católicas (en definitiva, la educación quedaba en manos del estado y la enseñanza religiosa no sería obligatoria), esta institución mantuvo importantes posiciones de poder, siendo el estado argentino un estado católico y no laico, como ocurriría en el vecino país de Uruguay. Los vínculos entre estado e Iglesia seguirían siendo importantes, especialmente en las provincias más conservadoras del norte argentino. Es necesario tener esto en cuenta - la retención por parte de la Iglesia de importantes cuotas de poder- para comprender los reordenamientos que ocurrirán ya entrado el siglo XX.

Otro punto importante a tener en cuenta sobre esta primera parte gira en torno a los orígenes de Sarmiento, perteneciente a una antigua familia que ya había dejado de ser acomodada y no conocía lujos en la pobre provincia de San Juan. Las «clases acomodadas» ${ }^{14}$ eran objeto de sus críticas, en las que también se manifestaba la tensión entre el interior relegado frente a un Buenos Aires pujante. Si bien sería un error pensar a Sarmiento por fuera del proyecto centralista que convergió en Buenos Aires luego del cierre del largo proceso de disputas por la organización (1820-1880), e inicio de la construcción del aparato estatal nacional, tampoco podemos dejar de lado la impronta del sanjuanino, quien desarrollara un dispositivo para la inclusión de los sectores más bajos de la sociedad: «la diferencia con el gesto de la dirigencia porteña es que su interés en triunfar contra la "ignorancia" contiene una íntima lealtad a sus coterráneos».15 Para él, la educación era un proyecto moral y popular, porque Sarmiento rechazaba la «meritocracia del saber y consideraba que una sociedad moderna es la que tiene el mayor número de ciudadanos instruidos».16 Por supuesto, no puede olvidarse que la otra cara del proyecto liberal y centralista era la eliminación de todos los sujetos que no entraran en el esquema de los ciudadanos educables. Gauchos e indios rebeldes, defensores de tradiciones propias, serían objeto de matanzas y asesinatos. La escuela popular era para los sujetos

\footnotetext{
14 Puiggrós, Adiós, Sarmiento, 146.

15 Puiggrós, Adiós, Sarmiento, 152.

16 Puiggrós, Adiós, Sarmiento, 147.
} 
que se adaptaran al nuevo orden. Como se afirma en el libro, nada «exculpa al Sarmiento defensor de la guerra, al que mandó a miles de negros, indios y pobres a morir en la Guerra del Paraguay, al que aplaudió la Campaña del Desierto». ${ }^{17}$

Personaje complejo y contradictorio, quizás en las cuestiones de género se encuentren las posiciones más avanzadas y democráticas de Sarmiento:

la preferencia de Sarmiento por las mujeres como educadoras significó un importante avance en una sociedad que apenas soportaba a las costureras y, en niveles sociales más bajos, reglamentaba el oficio de las nodrizas poniendo límites raciales al ejercicio de ese trabajo. ${ }^{18}$

En el cierre de la primera parte y sobre estos temas, la autora también nos marca señales para desarrollar nuevas preguntas de investigación, sobre el despliegue de las maestras norteamericanas ${ }^{19}$ en distintos puntos de la geografía del país, y el impacto que ese despliegue tuvo en los momentos fundacionales del sistema educativo argentino.

En el inicio de la segunda parte, la importancia del capítulo 11 es fundamental. Allí, la autora aborda el momento de la recomposición católica en la educación argentina, en un contexto occidental de avance de posiciones autoritarias y de desarrollo de redes políticas por parte de la Iglesia católica, sostenidas en los principios de la Encíclica Divini Illius Magistri de 1929 del Papa Pío XI. Todo esto tuvo un especial impacto en Argentina por ser sede del Congreso Eucarístico Internacional en 1934. Tres años más tarde, en 1937, la provincia de Buenos Aires aprobaba la introducción de la enseñanza religiosa obligatoria, sentando un precedente para que en 1943 la

\footnotetext{
17 Puiggrós, Adiós, Sarmiento, 152.

18 Puiggrós, Adiós, Sarmiento, 175.

19 Como simple aclaración, habría que decir que una de las decisiones que toma Sarmiento durante su viaje por Estados Unidos fue la de convocar a maestras norteamericanas para insertarse en el incipiente sistema educativo argentino como maestras pero también como formadoras de maestras. Una medida de una audacia notoria (pensemos que estamos hablando de mujeres angloparlantes y protestantes que llegan a una sociedad con un fuerte sometimiento de las mujeres, de fuerte raigambre hispánica y católica). Por todo esto, el éxito de la medida fue relativo. Ver especialmente páginas 172, 173 y 174 de Adiós, Sarmiento.
} 
obligatoriedad se extienda a todos los niveles y modalidades del sistema a nivel nacional.

Nos ubicamos en un contexto histórico muy diferente al de los momentos en los que la élite liberal y Sarmiento recortaron funciones a la institución eclesiástica. La política migratoria había promovido la llegada al país de trabajadores, quienes traían consigo las ideas revolucionarias que se desplegaban en Europa. El socialismo y el anarquismo se extendieron entre los trabajadores del país, muchos de ellos inmigrantes, por lo que el «orden conservador» ${ }^{20}$ tuvo que dar paso, luego de un momento de reformas políticas, al proceso de participación electoral popular. El saldo fue un período de gobiernos democráticos entre 1916 y 1930 encabezados por la Unión Cívica Radical, un partido político que representaba a los sectores medios, compuestos en gran parte por los trabajadores que habían logrado un ascenso social, por medio de un mercado interno en expansión y un sistema educativo inclusivo. El período radical se caracterizó por el ensanchamiento de la participación política más que por una transformación de los grandes ejes por los que transitaba el país, continuando lineamientos políticos y económicos fundacionales del estado y el reformismo de los primeros años del novecientos, reformismo del que surge, entre otras iniciativas, la ley electoral que viabiliza la victoria del radicalismo.

Pero este ciclo terminó abruptamente en 1930 con el primero de los golpes de estado que recibiría la democracia argentina a lo largo del siglo XX. Sectores de la élite aprovecharon el desgobierno producido por un anciano presidente que ya no garantizaba la conducción de los destinos nacionales y el contexto de crisis mundial, para volver a ordenar la vida política según los criterios de la clase rentista y agroexportadora. Esta vez, con un reordenamiento de las alianzas en los que estaba presente, junto al poder militar, el nacionalismo conservador y la Iglesia católica, en un contexto de gobiernos de facto, fraudulentos o proscriptores, por un período de quince años (1930-1945). En síntesis, la Iglesia

\footnotetext{
${ }_{20}$ Si bien la organización nacional tenía un formato republicano de división de poderes desde la Constitución de 1853, la democracia era «simulada», en el sentido de que el poder rotaba entre los representantes de la oligarquía, quienes dirimían sus disputas mediante acuerdos políticos o mediante la violencia, simulando un mecanismo de representación popular inexistente, caracterizado por el fraude electoral, la compra de votos, etc. [Natalio Botana, El orden conservador (Buenos Aires: Hyspamérica, 1985)].
} 
católica recobra porciones de poder que había perdido, y aprovechando un contexto de crisis, logra imponer las demandas por las que había sido derrotada cincuenta años antes frente al liberalismo.

Esta situación de fortalecimiento de las posiciones educativas de la Iglesia católica fue el contexto del proyecto de gobierno encabezado por Juan Domingo Perón en 1945. Proyecto político que se construyó en oposición a los sectores económicos concentrados, los partidos políticos tradicionales, y la embajada de los Estados Unidos: las alianzas de Perón para su futuro gobierno constaban principalmente de la clase trabajadora en su representación institucional (los sindicatos), los militares (Perón era militar) y la Iglesia católica.

En base a este sistema de alianzas, el nuevo gobierno democrático ratificó la situación heredada, por lo cual hubo continuidad en la enseñanza religiosa en las escuelas públicas nacionales, hasta que el gobierno peronista entrara en disputa con la Iglesia, hacia el final de su segundo mandato. Entre otras consecuencias de la ruptura, se terminaba la obligatoriedad de la enseñanza religiosa. Enfrentada con el gobierno, la Iglesia católica formaría un nuevo sistema de alianzas con un sector militar, produciendo golpes armados contra el gobierno justicialista que costaron vidas civiles y terminaron con su derrocamiento en septiembre de 1955, inaugurando un nuevo ciclo de dictaduras cívico militares.

La participación principal de la Iglesia católica en el frente antiperonista habilitaría posiciones de poder desde las que se exigieron una serie de demandas relacionadas con facilitar el despliegue de las ofertas educativas privadas. El punto de inflexión fue durante el año de 1958, cuando a través de una serie de decretos y leyes, el gobierno nacional otorgó la potestad de expedir títulos habilitantes a las universidades privadas. Hasta ese momento, esto había sido responsabilidad exclusiva de las universidades estatales, constituyendo esta ley un claro beneficio para el mercado de la educación privada.

En síntesis, podemos afirmar que el período que se abre con la década del '30 es de constantes avances de la Iglesia católica y de la educación privada, que desde esos momentos ya eran parte de un mismo grupo de intereses. Vale recordar que las bases en las que se asientan 
esos avances son bases firmes, con una fuerte penetración social de la Iglesia católica, tanto en los sectores populares como en las clases dirigentes.

Podríamos definir con Puiggrós a este período como de «estancamiento», si se lo compara con la expansión educativa del sector público en el período anterior, desde la fundación del sistema hasta los '30. Ese estancamiento, en donde en gran medida la educación pública resistió los embates privatizadores a partir de esa matriz estatalista fundacional, llegaría hasta la década del '70, momento que la autora no duda en denominar como de «destrucción del sistema escolar moderno», ${ }^{21}$ título de la tercera y última parte del ensayo.

La tercera parte del libro analiza las tensiones en las últimas décadas en torno al derecho a la educación, especialmente como saldo del ingreso pleno de la Argentina al paradigma neoliberal, empujado por la dictadura cívico militar (1976-1983), que ponía al país en sintonía con los procesos dictatoriales de la región. De manera detallada, analizando la situación global, regional y local, en esta tercera parte la autora despliega su conocimiento de los debates más actuales del mundo de la educación, con referencias muy interesantes en especial sobre el caso norteamericano.

Si desde los inicios de esta historia teníamos a la idea de empate como un concepto bastante claro de las disputas entre el estado como garante de la educación y el mercado y la educación como mercancía, podemos afirmar que a partir de la década del '70 ese equilibrio se rompe en favor de los sectores privados, y en perjuicio de todo un sistema de educación público nacional que se fragmenta al punto de poner en duda la idea de sistema.

Para las últimas décadas del siglo, el sistema educativo argentino, inspirado en el ideal sarmientino con una fuerte preeminencia de lo público-estatal, entró en crisis por las políticas implementadas por los gobiernos neoliberales desde la última dictadura cívico militar. El más fuerte impacto al corazón del modelo del estado docente fue la imposición de la transferencia de los servicios educativos nacionales al ámbito

${ }^{21}$ Puiggrós, Adiós, Sarmiento, 227. 
de las provincias, imposibilitadas financieramente para hacerse cargo del gasto que esto implicaba, lo cual repercutió de manera directa en una disminución de la calidad educativa estatal y un fortalecimiento del sector privado.

El saldo del proceso militar fue un evidente debilitamiento de los sectores que sostenían posiciones favorables a la educación laica, estatal, pública y popular. Diezmados por la muerte, la desaparición o el exilio, esos sectores no lograron articular posiciones contra un liberalismo conservador que representaba los intereses de la Iglesia católica argentina y de la educación privada. El Congreso Pedagógico de 1984 fue la instancia de la reapertura democrática en la que se manifestaron las distintas posiciones. Convocado por el gobierno radical de Raúl Alfonsín, el congreso apuntaba a insuflar al nuevo gobierno del espíritu fundacional del estado argentino en su acepción más liberal y progresista.

Como era de esperarse, el resultado del congreso fue favorable a los sectores que habían llegado fortalecidos (Iglesia católica y educación privada), paradójicamente distantes de los lineamientos ideológicos del gobierno que lo había convocado. Pero lo que es interesante para destacar es en qué aspectos fue esa ganancia. Para decirlo de otro modo, los sectores católicos no pudieron imponer en el congreso la enseñanza religiosa en las escuelas estatales, una vieja reivindicación enarbolada desde la derrota del Congreso Pedagógico realizado cien años antes, gestor de la ley 1420 con enseñanza religiosa por fuera del horario escolar obligatorio, que dicho sea de paso ni siquiera pudo ser impuesta por la última dictadura, la más autoritaria y aliada de la jerarquía eclesiástica.

La gran victoria se dio por el lado del rol que asumiría el estado con relación a lo público. Como dice la autora, se acordó «que las escuelas públicas no serían más "del estado" sino que este quedaría como uno de sus gestores», ${ }^{22}$ en tanto las privadas también serían consideradas escuelas públicas de gestión privada. De esta manera, se rompía con una de las tradiciones más arraigadas en la sociedad argentina, que vinculaba a lo público con lo estatal, y que consideraba a la educación pública como

22 Puiggrós, Adiós, Sarmiento, 225. 
la mejor opción para la educación de sus hijos. Si por un lado logró resistir la idea de que la educación religiosa no debía ser obligatoria, por el otro sí aparecía como una posibilidad el hecho de que la educación podía ser tanto estatal como privada. Logrando estos consensos y llevando al estado hacia posiciones cada vez más subsidiarias fue la forma que encontraron los sectores eclesiásticos y privatistas para imponer sus demandas.

La ruptura de la idea de lo público fue una de las principales victorias del discurso neoliberal, impuesto a sangre y fuego durante la última dictadura cívico militar, y allanando el camino para el posterior ciclo neoliberal, triunfante por el voto popular, que profundizó la desarticulación del sistema educativo y la plena incorporación de los valores del mercado en la educación, tales como los conceptos de calidad y evaluación. O para decirlo con las palabras de la autora, «la distancia entre el lenguaje economicista y el lenguaje pedagógico se acortó peligrosamente ${ }^{23}$ en los años de consolidación neoliberal, tras la caída del bloque de la Europa del Este y la hegemonía capitalista.

En el capítulo catorce, que inicia la tercera parte del libro, la autora pone en juego de manera muy aguda conceptos de economía política, a través de autores como Mannheim, Hayek, Keynes y Friedman, para describir el panorama político y económico en el que la educación comenzaba a regirse por las lógicas del mercado, pasando de la concepción del derecho a la del bien transable. En el contexto de mercantilización de la educación, «se ha instalado una maquinaria de reelaboración del discurso educativo que va destruyendo los soportes simbólicos de la educación moderna».24

De lectura indispensable, este capítulo nos lleva, a través de las figuras de Horace Mann y John Dewey, a la situación educativa de Estados Unidos, para ejemplificar las disputas entre el estado y el mercado y mostrar cómo operan los sectores que conciben a la educación como un negocio y que utilizan una batería de conceptos como los de eficiencia, eficacia, equidad, accountability, management, arancelamiento, calidad y evaluación. Esta última, idea central del discurso

\footnotetext{
${ }^{23}$ Puiggrós, Adiós, Sarmiento, 223.

${ }^{24}$ Puiggrós, Adiós, Sarmiento, 236.
} 
educativo neoliberal, acuñada como contraparte de otra idea representativa de este discurso: la crisis educativa. Si hay crisis lo que hay que hacer, desde esta perspectiva, es realizar una correcta medición a través de herramientas de evaluación, a partir de las cuales obtener la información necesaria para realizar las modificaciones en el sentido de mejorar los resultados. Los actores y los programas que encarnan estas discusiones son expuestos con nombre y apellido, mostrando al escenario norteamericano como un lugar de tensiones y disputas donde pueden reflejarse perfectamente aquellas que se producen en diversos países a lo largo y a lo ancho del globo.

Algo que la autora se preocupará por dejarnos en claro en el desarrollo de este capítulo es el hecho de que los docentes son los agentes contra los que específicamente apuntan las políticas educativas globalizadas, entre las que se incluye la evaluación. De esta manera, de la mano de los avances tecnológicos y de un diagnóstico desfavorable del desempeño de los docentes producto de la aplicación de las evaluaciones, se despliega toda una industria proveedora de paquetes y herramientas tecnológicas estandarizadas, que garantizarían una infalibilidad que los docentes no pueden asegurar.

Por supuesto que todo esto no puede desvincularse de la lectura económica que propone la autora y que sitúa estas políticas en un contexto de retraimiento de los estados nacionales y, por lo tanto, de aplicación de políticas de ajuste fiscal entre las que se encuentra claramente el recorte del salario docente como forma de disminución del gasto en educación. En definitiva, como dice la autora, evaluar, "ahora resulta un negocio redondo». ${ }^{25}$ Los estados reducen gastos con la excusa de un bajo rendimiento de los docentes, y las empresas desarrollan negocios millonarios.

Otro elemento fundamental de esta tercera parte aparece de la mano del análisis del caso chileno, caso paradigmático de los avances privatizadores de la educación en América Latina, y tiene que ver con la introducción en América Latina, vía Chile, de lógicas de financiamiento de la educación extendidas en otras geografías, como Estados Unidos o Europa, pero que en Sudamérica conformaban toda una

\footnotetext{
${ }^{25}$ Puiggrós, Adiós, Sarmiento, 244.
} 
novedad: el arancelamiento de la educación por parte del sistema de bancos nacionales e internacionales. Si bien en países como Argentina estas lógicas no han tenido implementación, probablemente por las fuertes tradiciones de educación pública de este país, es un dato que no debe dejar de mantenerse como un alerta. De hecho, la tradición educativa chilena y la argentina tienen un origen muy similar, como se desarrolla desde los primeros capítulos del libro a través de la figura de Sarmiento. Lo cual es una muestra de que ningún sistema educativo está exento de los procesos privatizadores.

El capítulo 16 retoma el panorama desarrollado en los dos anteriores, para realizar un recorrido específico por el proceso neoliberal que atravesó la educación en Argentina, con una lectura minuciosa de los actores involucrados en los procesos desde la salida de la dictadura, los conflictos sociales y las resistencias por parte de colectivos políticos y sindicatos docentes. Estos últimos, junto con organizaciones sociales y políticas, fueron actores protagonistas de la crisis que atravesó el país en los inicios del siglo XXI, conocida como la «crisis del 2001», a partir de la cual se abrió un nuevo ciclo político que, entre otras cuestiones, promovió una nueva reforma educativa que intentaba subsanar la situación heredada del proceso neoliberal.

Esta última reforma podría ser abordada en términos de las políticas educativas desarrolladas por el nuevo gobierno, evaluando en qué medida pudo lograr el esperado reposicionamiento del estado hacia un rol más protagónico. Probablemente los diagnósticos sean divergentes según la afinidad de quien realice el análisis con las políticas implementadas. Pero considero que Puiggrós aporta un elemento fundamental, que trasciende la cuestión de las medidas legales implementadas y su mayor o menor eficacia, que tiene que ver con la cuestión de los derechos humanos, un tema central para la historia reciente argentina. La autora define como la acción pedagógica más importante del gobierno de Néstor Kirchner la «política referida a los derechos humanos, especialmente la reapertura de los juicios a los represores de la última Dictadura». ${ }^{26}$ Leída rápidamente, la frase podría pasar desapercibida. Por eso quisiera alertar al lector para detenerse en ella, porque en esas palabras se condensa en gran parte una de las políticas del

\footnotetext{
26 Puiggrós, Adiós, Sarmiento, 289-290.
} 
estado nacional argentino más importantes desde la recuperación de la democracia (1983), pero también allí está en gran parte el legado intelectual de Adriana Puiggrós: en romper las fronteras de la pedagogía, sacándola de los muros de los sistemas educativos para comprender procesos políticos, sociales y culturales como parte de los discursos pedagógicos.

\section{PALABRAS FINALES}

A modo de síntesis, puede decirse que Adiós, Sarmiento se inicia con las discusiones político-pedagógicas del siglo XIX y concluye en la situación educativa actual global, regional y local, con un recorrido centrado en la historia del sistema educativo argentino, enfocando principalmente la relación entre lo público y lo privado o, para decirlo de otra manera, entre la idea de la educación como un derecho y la concepción de la educación como un negocio.

En el caso argentino, esas relaciones están permeadas por las tensiones del proceso de secularización que enfrentaron a la élite liberal con la tradición de la Iglesia católica, presente desde los tiempos de la colonia como institución que estructuraba la vida social. Al enfrentarse a las posiciones que promovieron una centralización de la iniciativa educativa por parte del estado nacional, configurando un «estado docente», la Iglesia católica argentina asumió posiciones privatistas a lo largo del siglo XX, liderando a los sectores que promovieron la desregulación y la privatización de la educación y que lograron imponer sus demandas hacia el final del siglo.

El libro de Puiggrós es un ensayo ampliamente documentado, en el que la autora muestra su oficio de historiadora de la educación, sin encerrarse en moldes y formalidades. Puiggrós escribe porque quiere decir, porque quiere denunciar y discutir, y porque desde la escritura asume la función militante que ha desarrollado a lo largo de su vida. De hecho, a partir de esto podría pensarse al libro como tres libros al mismo tiempo: un trabajo académico de historia y política de la educación, un ensayo y un manifiesto político-pedagógico. En algunos capítulos esta variación de registros puede resultar árida, especialmente en la primera parte, la más profusa en detalles históricos en los que la autora despliega su erudición. Dicho sea de paso, esto es un signo que sin dudas es distintivo de 
Puiggrós: la pedagoga encuentra entre sus obsesiones intelectuales al liberalismo decimonónico y sus problemas, a las tensiones entre la filosofía de la libertad y la necesidad de consolidación de los aparatos estatales latinoamericanos, y a Sarmiento y sus combates en la construcción de la nación argentina.

Los tres registros están presentes en la obra, y cualquiera de los tres, o la totalidad que conforman, puede ser una motivación para su lectura. Acostumbrada a la dinámica política de la discusión, el debate y los consenso, quien lea puede tener por seguro que las posiciones de la autora son explícitas, y los argumentos discutidos son desarrollados ampliamente, porque «combatir con un autor es un acto de respeto». ${ }^{27}$

Este trabajo podría ponerse en sintonía con otro anterior ensayo, El lugar del saber. Conflictos y alternativas entre educación, conocimiento y política (2003). ${ }^{28}$ Como en Adiós, Sarmiento, El lugar del saber presenta una radiografía de la educación argentina desde sus orígenes hasta el presente. También alterna el estilo académico con el ensayo y la opinión política, con notas de actualidad que se enhebran en un relato histórico, ya con la preocupación que persiste en Adiós, Sarmiento por la educación en el neoliberalismo.

Entre El lugar del saber y Adiós, Sarmiento media todo un ciclo político en el que desplegaron su acción gobiernos con preocupaciones por restablecer una idea de educación como derecho. En la introducción de esta presentación, en un breve recorrido por la bibliografía de la autora, decíamos que este último ensayo está escrito con la urgencia de la batalla de ideas y con la experiencia de los intentos por expandir la inclusión educativa. En este sentido, la lectura de este ensayo puede ser un buen ejercicio para hacer una revisión crítica de las políticas que procuraron garantizar el pleno ejercicio del derecho a la educación, en el proceso de balance que necesariamente nos debemos a ambos lados del Atlántico, para volver a impulsar políticas públicas que vayan en el sentido de la justicia educativa.

\footnotetext{
27 Puiggrós, Adiós, Sarmiento, 171.

28 Adriana Puiggrós, El lugar del saber. Conflictos y alternativas entre educación, conocimiento y politica (Buenos Aires: Editorial Galerna, 2003).
} 
En definitiva, tanto como panorama de la historia y la política del sistema educativo en Argentina, con un énfasis en las relaciones entre lo público (representado por un estado garante del derecho a la educación) y lo privado (representado por la Iglesia católica), o como forma de ver al caso argentino como un ejemplo posible en el devenir de la actual situación global de la educación, o ambas, no queda más que invitar a la lectura de esta obra.

Ignacio Frechtel Universidad de Buenos Aires ignaciofrechtel@gmail.com 